\title{
Urban nature protection measures evaluated by opinion poll respondents
}

\author{
Igor Pryadko, ${ }^{1, *}$ \\ ${ }^{1}$ Moscow State University of Civil Engineering, 26, Yaroslavskoe shosse, 129337, Moscow, Russia
}

\begin{abstract}
The article addresses the findings of the poll, conducted by lecturers and students of the National Research Moscow State University of Civil Engineering. The poll objective was to identify the level of ecological culture demonstrated by the residents of Moscow, the Russian capital and a megacity. Residents of its old and new administrative districts were among the respondents. The author verifies the scope and extension of such concepts as ecological culture and environmental safety, sheds light on the structure of environmental safety. The responses, given by the respondents, are used in the rating of environmental hazards of which air pollution is a number one threat. Moreover, the poll addressed such problems as domestic waste removal, pollution of Moscow rivers, lakes, ponds and other water bodies with waste water. Besides the polling method, employed by the author, he used the retrospective analysis of news items. Moreover, environmental monitoring results and opinions, expressed by the authors of research articles, were analyzed; methods of deduction, induction, classification and split of concepts were also used by the author.
\end{abstract}

\section{Introduction}

Today, a comfortable environment, that accommodates well-executed architectural and urban planning solutions, is a problem to be tacked by urban authorities. The civil society is also involved in the environmental protection discourse. More often than not, a decision to build an industrial facility, a shopping mall or any other piece of architecture is made with regard for the viewpoints expressed by urban residents, as any construction project approval is preceded by multilevel public hearings $[1,2,3]$. However, does each participant of public hearings have a sufficient level of environmental culture? This issue is addressed by the author, and the article is to facilitate a solution to this problem.

In the meantime, environmental problems aggravate due to growing cities and their population, let alone the emergence of large suburbs and agglomerations [4, 5]. The 2008 census was a demographic watershed. According to the United Nations, back then urban population equaled and exceeded rural population [6]. The biota and the natural environment have been exposed to higher loading since then. Urban transport operates at its limits, and solid waste removal and recycling become a real challenge [7, pp. 87-91]. Soil and air are polluted in urbanized areas, waste water flows into water bodies whose bottoms

* Corresponding author: priadcko.igor2011@yandex.ru 
accumulate heavy metals. Urban living has turned into a permanent contradiction and compromise. Therefore, the reproach brought upon the contemporary civilization by Yu.K. Efremov, an ethnologist and geographer, seems quite fair, as he accuses humans of "predatory draining natural resources and disfiguring landscapes by wars" [8, quoted in 9].

Social science and its instruments are to tackle these problems. Instruments of social science enable researchers to analyse the condition of urban environments, preserve their biotas and do away with contaminants that have invaded the geosphere shells. Urban residents, who participated in our poll, consider environmental protection as one of the most important problems. This opinion was expressed in 2020 by the respondents of the poll, conducted among lecturers and master students of the Moscow State University of Civil Engineering. $80 \%$ of the respondents believe that problems of urban ecology are particularly relevant [10].

The author also addresses the findings of the opinion poll, conducted among bachelor and specialist degree students of several Moscow engineering universities.

\section{Materials and methods}

The questions, listed in the previous paragraph, were asked within the framework of an opinion poll, conducted in March 2020 among the lecturers and students of the Moscow State University of Civil Engineering. 143 young residents of the Russian capital were chosen as respondents. Most of them were students of the Moscow State University of Civil Engineering and other Moscow engineering universities. That's why the majority of the respondents answered that they had «incomplete higher education» or «vocational secondary education". Principal socio-demographic characteristics of the respondents (sex, education, age) are provided in the charts below (see Fig. 1-4).

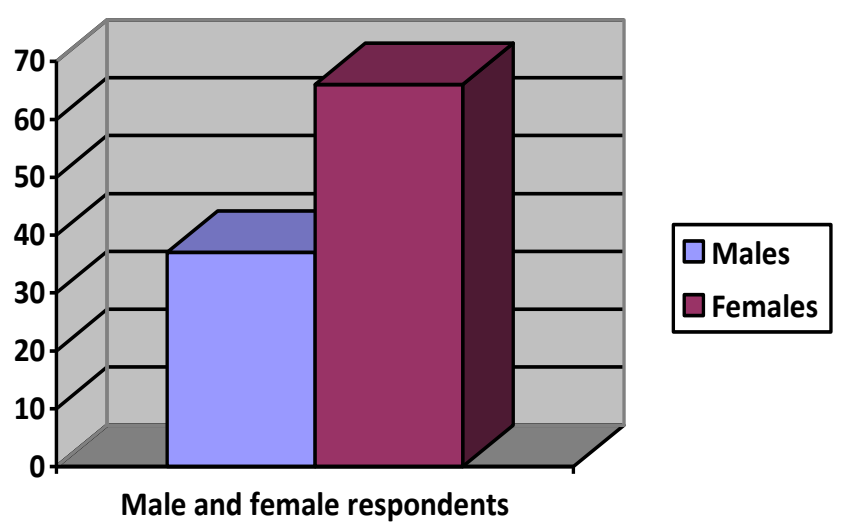

Fig. 1. Male and female respondents. 


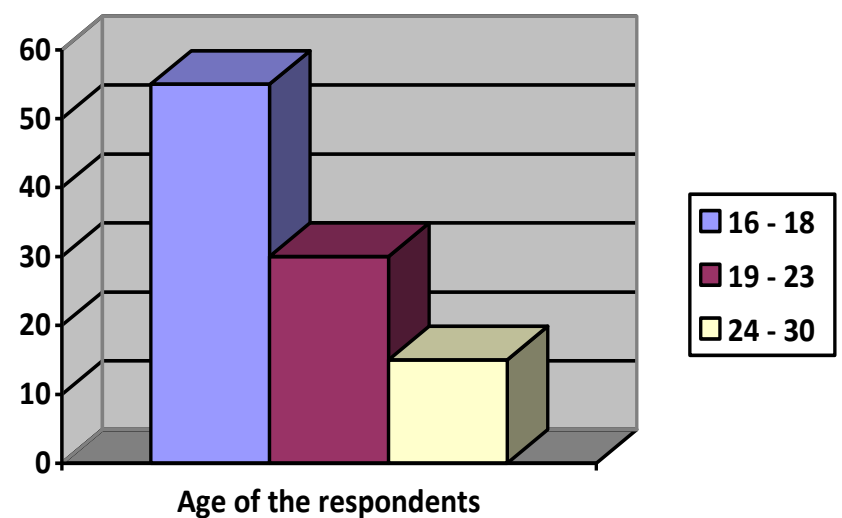

Fig. 2. Age of the respondents. According to the chart, respondents are young.

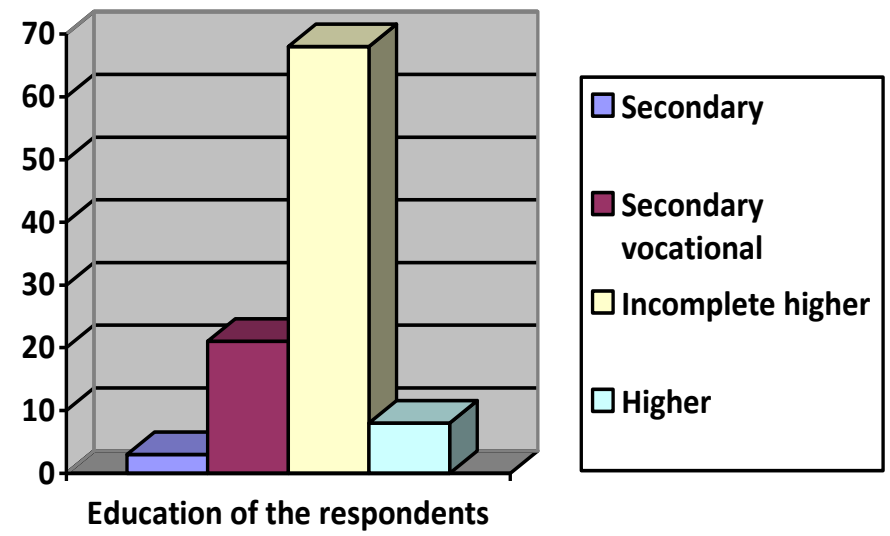

Fig. 3. Education of the respondents.

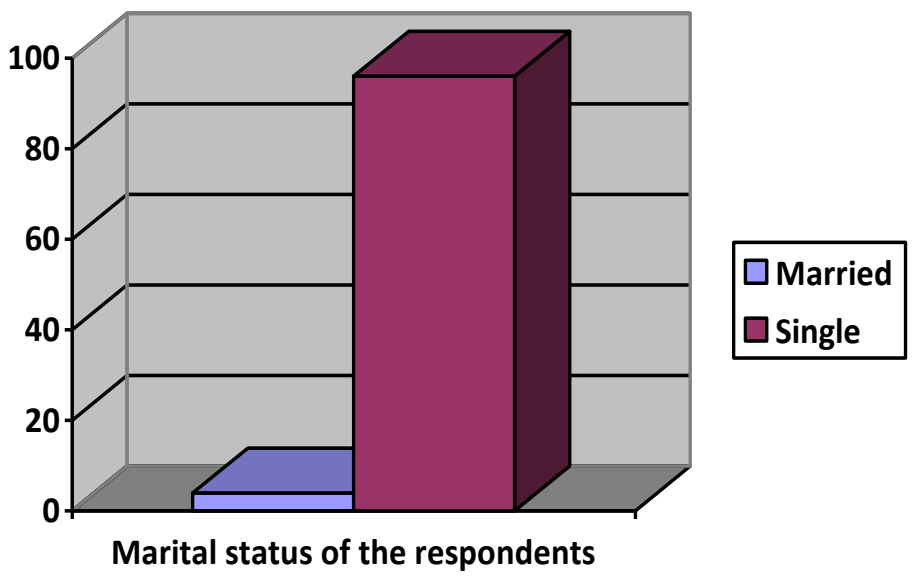

Fig. 4. Marital status of the respondents.

A written questionnaire was chosen as the main data collection instrument. Principal research methods, employed in this project, include the analysis of poll findings, the 
retrospective analysis of sources, such as news items, expert opinions, published in research journals, and the general research method used to identify the scope and content of concepts.

\section{Results}

A succession of environmental protection measures is something that can make lives of urban residents comfortable and convenient. They should be applied a joint effort of state institutions and the civil society. Every urban and rural resident must be scrupulous and caring about the natural environment. To make this happen, actions should be taken to develop environmental culture. Therefore, educational programmes that nurture the cultural development of students and schoolchildren, gain in importance, because present-day students, schoolboys and schoolgirls are the future citizens who will assume the responsibility for the environment and living standards, that are pre-determined, inter alia, by such characteristics of residential areas, as biosphere compatibility, comfort, and safety.

Let's explain the terms that are the essential for this research project. Biosphere compatibility is a system of socio-economic and humanitarian mechanisms that facilitate comfortable interactions between humans, the technosphere that they have created, and the environment. In this sense, researchers, specializing in urban environments (for example, L. Rozantseva and A. Boltaevsky), "solve practical problems dealing with the development of humans, technologies, organizations, commodities and the biosphere" [11] (see also [12]). A biosphere compatible environment urges for the ideas aimed at the improvement of present-day economic instruments used to develop humans and to transform technologies, and organizations into instruments that foster the progressive and harmonious development of humans, the biosphere and the technosphere.

We understand safety as comfort accompanied by minimal negative consequences. Discomfort, traumatism, morbidity, shrinking life span, material damage are the criteria of negative impacts produced by the environment on humans. Problems of the visual ecology, aesthetically and functionally friendly urban environments, likeness of built-up urban areas, design of urban leisure areas gain in importance in a contemporary megalopolis. Our questionnaire also addresses this problem.

Economic behaviour, being a constituent of environmental culture, entails a system of actions and measures aimed at environmental protection and management. The level of culture, demonstrated by the respondents, is determined by the extent of their involvement in environmental protection actions. Their answers to the question about the willingness to participate in such actions are analyzed in Fig. 5. 


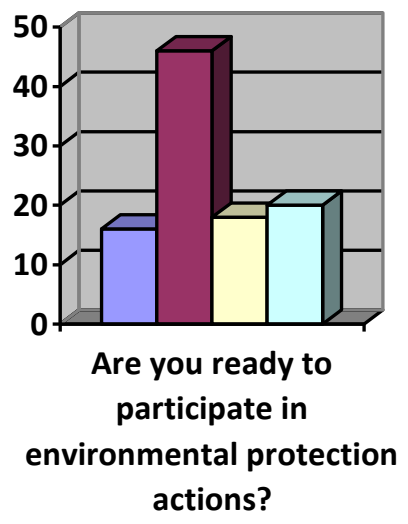

\begin{tabular}{|l|}
\hline Yes \\
$\square$ No \\
$\square$ Rather yes than \\
no \\
$\square$ Rather no than \\
yes
\end{tabular}

Fig. 5. The breakdown of answers to the question «Are you ready to participate in environmental protection actions?».

The respondents were to answer the question about their participation in volunteer clean-up events. $27 \%$ of the respondents have taken part in such clean-up actions. $37 \%$ have never participated in such events. $36 \%$ do it seldom or very seldom (Fig. 6).

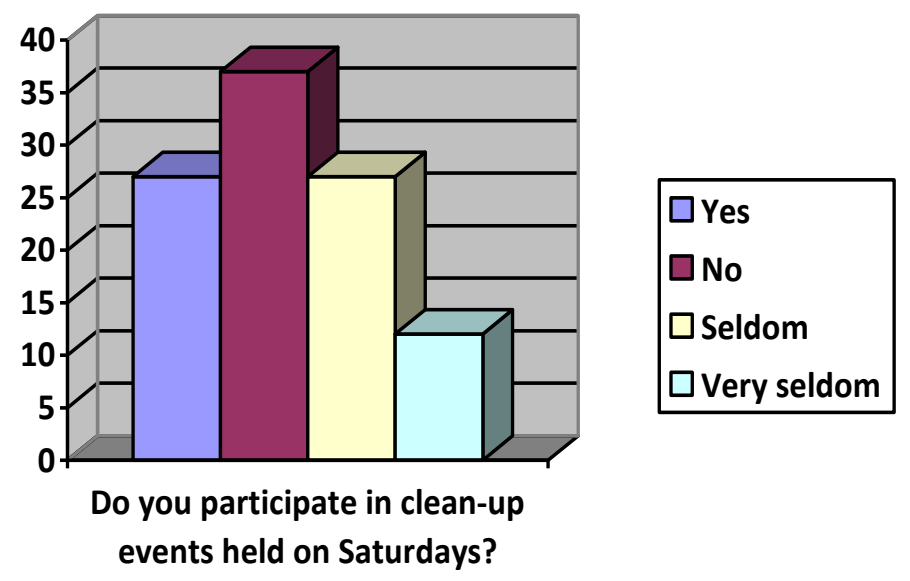

Fig. 6. The breakdown of answers to the question about the participation of respondents in voluntary clean-up events, which are usually held on Saturdays and Sundays.

The answers, given by the respondents, have proven that most of them realize the importance of «their minor contributions» for the restoration of the environmental balance in residential areas. $65 \%$ of the respondents follow the rules that govern the human conduct and co-existence. After analysing the poll findings, the author revised the scope and content of the concept of "environmental culture": it is a part of human culture and a system of social relations, societal and individual moral and ethical norms, views, mindsets and values that govern relations between humans and nature.

Human environmental culture manifests itself in the willingness of individuals to take minor steps towards order and cleanness in their homes, streets and neighbourhoods. This issue was addressed by several questions in our questionnaire. For example, $37 \%$ of our respondents express their willingness to sort their waste, while $48 \%$ impose particular conditions on this procedure. $15 \%$ are not going to do it under any circumstances (Fig. 7). 


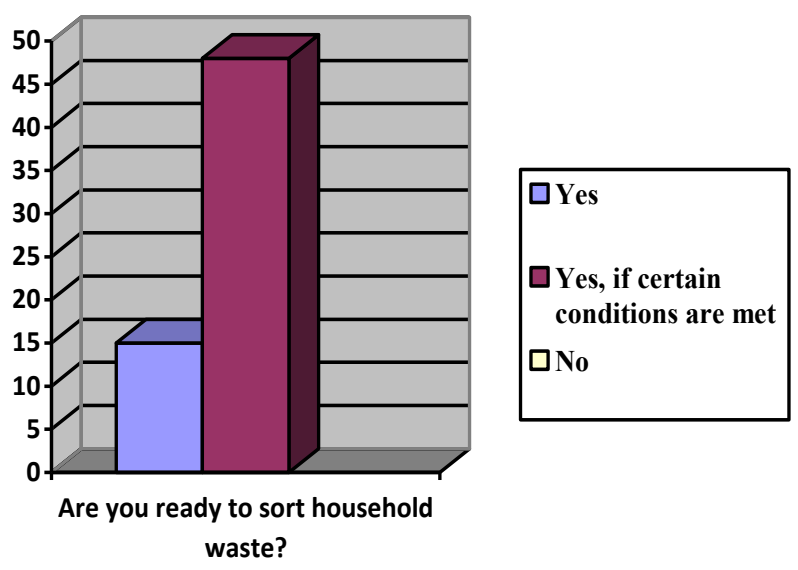

Fig. 7. Respondents' willingness to sort waste.

In one of the questionnaire questions, respondents were asked to give a general assessment of environmental conditions in the city of their residence. Although they all reside in Moscow (including its newly annexed neighbourhoods), the judgements, expressed by the respondents, vary (see. Fig. 8).

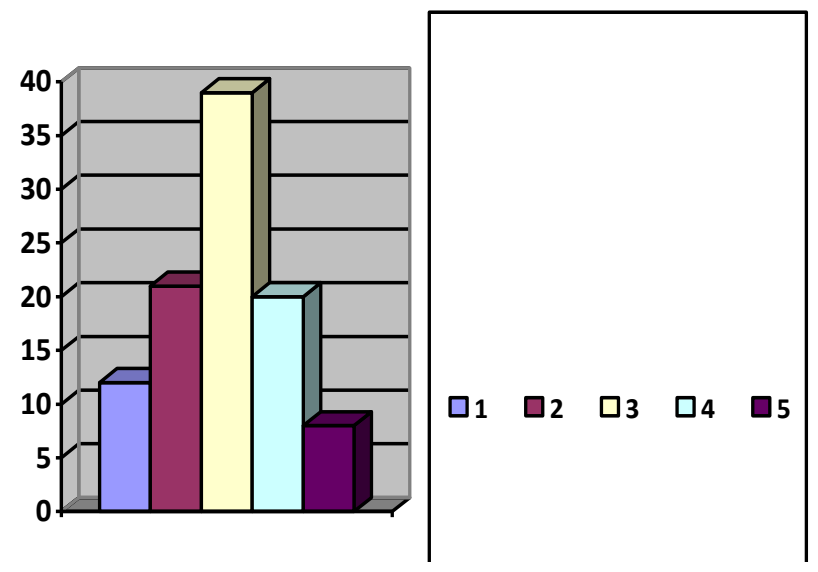

Fig. 8. Environmental conditions in the megalopolis on a scale of five.

\section{Discussion of questionnaire findings}

Having analysed the answers to the question about environmental conditions, we arrive at a conclusion that the environmental situation differs in different neighbourhoods of the Russian capital. However there is no benchmark for the respondents to refer to when analysing the natural environment. Its complexity and heterogeneity arise from the heterogeneous structure of urban environments. Natural and anthropogenic sub-systems of cities are split into lower-level ones, which are, in their turn, subdivided into further lowerlever sub-systems. The balance and equilibrium of these subsystems can serve as the criteria for the analysis of the environmental condition of a city (the way it works in [13]), as according to the theories of urban ecology, the operation of urban systems is predetermined by the processes that are underway within its sub-systems and the intensity of direct positive and negative links and feedbacks between its sub-systems. The assessment 
of a city as an ecological system, performed by a respondent, represents the integral assessment of its sub-systems. Indeed, on the one hand, humans, animals, birds, insects reside in cities, and autophytes grow there, as well. On the other hand, any city has flows of energy and substances, created and controlled by humans. Their effect on humans may turn out to be potentially dangerous. If outcomes of human activities do not damage nature, the environmental situation is positive. Otherwise, this situation must be assessed as "unsatisfactory." This is how $21 \%$ of the respondents assessed the environmental situation in Moscow.

A city is a non-equilibrium system, because its development is determined by human activities rather than the laws of nature. A city is a product of positive and destructive efforts of residents applied over the course of years. Therefore, the condition of urban systems and its assessment may vary.

The behaviour of urban residents must help to preserve the micro-structure of environmental frameworks. The questionnaire had an environmental test that contained questions about the respondents' willingness to take action to preserve the environmental balance in urbanized areas and to take part in street cleaning actions. These questions were asked in a poll conducted by the students and lecturers of the Moscow State University of Civil Engineering. The answers have proven that local measures, aimed at environmental protection and urban area cleaning, must be supported by a system of hygienic, technological, biological, engineering, planning and organizational nature protection actions [14]. Containment, purification, and utilization of hazardous discharges, effluents and wastes must be performed by specialized organizations and industrial enterprises, while urban areas can be cleaned by local residents willing to remove household waste.

Combustion emissions are maximal when vehicles stop at traffic lights without stalling their engines or when they rev the engines of their cars after the set off. The respondents who participated in our poll are young and fast moving. Their need to move across the city is quite high. Many of our respondents travel by car. Community-minded individuals appreciate speed and comfort. Some respondents confessed that they were not ready to swap their cars for public transport to reduce combustion emissions into the surface layer of the atmosphere. Urban planning actions aimed at reducing the concentration of exhaust gases in crowded areas are important for protecting the air from motor car emissions [14]. These actions include construction of multilevel road junctions, relief roads, byways, as well as using the subterranean space to accommodate garages and parking lots (subterranean parking lots are built in the New Moscow) $[15,16,17]$, sporadic building activities in residential areas. However non-disposable bags and waste sorting should be considered as minor measures towards achieving the main goal, or the design of biosphere compatible urban spaces $[18,19]$.

\section{Conclusions}

The article analyses the findings of an opinion poll, conducted by lecturers and students of the Moscow State University of Civil Engineering in February and March 2020. The poll was focused on the assessment of the urban environment in different Moscow neighbournoods. The poll findings helped the author to revise the list of challenges and problems to be tacked by the urban authorities. The author also analysed the actions dealing with urban ecology and design. The poll findings were used to analyse the environmental culture demonstrated by urban residents. The poll findings can be used in the course of any environmental protection action in major megalopolises, in general, and in Moscow, in particular. 


\section{References}

1. Z.I. Ivanova, T.N. Magera, Public hearings procedure improvement: social and legal aspects (ASV Publ., 2020)

2. Z.I. Ivanova, N.V. Danilina, MATEC Web of Conferences 251, 05028 (2018) https://doi.org/10.1051/matecconf/201825105028

3. Z.I. Ivanova, N.V. Danilina, M.A. Slepnev, E3S Web of Conferences 91, 05012 (2019) doi: https://doi.org/10.1051/e3sconf /2019910

4. A. Mottaeva, A. Borisova, E3S Web of Conferences 138, 02015 (2019) https://doi.org/10.1051/e3sconf/201913802015

5. A.V. Bataev, A.A. Gorovoy, A.B. Mottaeva, Proceedings of the 32nd International Business Information Management Association Conference, IBIMA 2018 - Vision 2020 (2018)

6. I.P. Pryadko, Urbanistika 2, 38-51 (2017) DOI: 10.7256/2310-8673.2017.2.23036

7. I.Yu. Kozina, Proceedings of international and all-Russian science and practical conference "Problems of innovative biosphere compatible socio-economic development of the construction industry, utilities sector and road building» (BGITU Publ., 2015)

8. Yu.K. Efremov, Priroda 8 (1966)

9. L.N. Gumilev, Ethnogenesis and the biosphere of Earth (Moscow, AST Publ., 2007)

10. S.A. Mudrak, J. of Economy and entrepreneurship 10 (2020)

11. L. Rozantseva, About biosphere compatible cities. Publication certificate № 215121500626, https://proza.ru/2015/12/15/626

12. S. Kurolap, O. Klepikov, P. Vinogradov, V. Gritsenko, Baltic region 8(4), 108-124 (2016) doi: 10.5922/2079-8555-2016-4-10

13. V.V. Vladimirov, Urban ecology (Moscow, MNEPU Publ., 1999)

14. A.A. Boltaevsky, Social Dynamics 8, 23-37 (2015) doi: 10.7256/24097144.2015.8.15998

15. A. Mottaeva, As. Mottaeva, J. of Economy and entrepreneurship 4-1(69), 1124-1129 (2016)

16. A. Mottaeva, J. of Economy and entrepreneurship 2(103), 365-370 (2019)

17. V. Holodkova, A. Mottaeva, T. Pokrovskaya, E3S Web of Conferences 164, 11043 (2020) https://doi.org/10.1051/e3sconf /202016411043

18. N.M. Kozina, Proceedings of international and all-Russian science and practical conference "Problems of innovative biosphere compatible socio-economic development of the construction industry, utilities sector and road building» (BGITU Publ., 2015)

19. A. Mottaeva, J. Ćetković, Advances in intelligent systems and computing 692, 1151 (2017) 